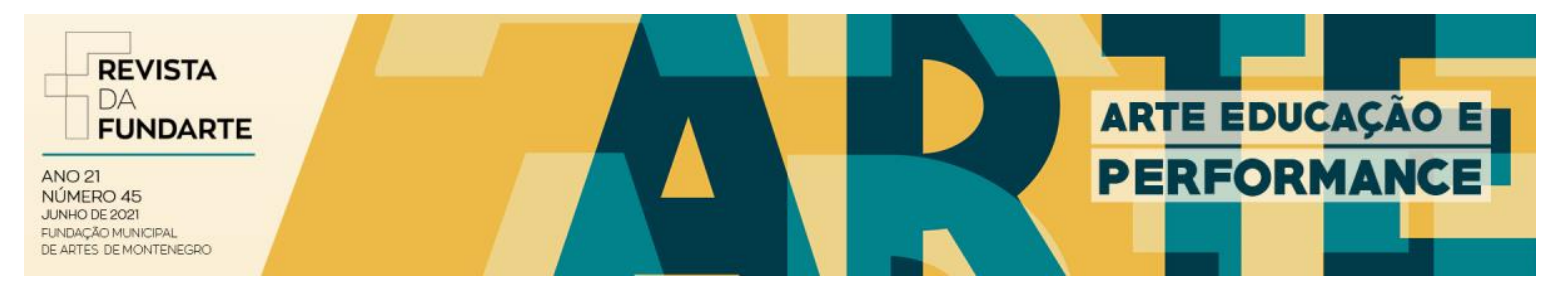

\title{
POÉTICA DA AUTOFICÇÃO NA PERSPECTIVA YIN YANG E UMA MICROCULTURA DIALÉTICA E HOLÍSTICA DO CORPO
}

\author{
André Martins Ziegler
}

DOI: $10.19179 / 2319-0868 / 746$

Disponível em: http://.seer.fundarte.rs.gov.br/index.php/revistadafundarte/index> 30 de junho de 2021. 


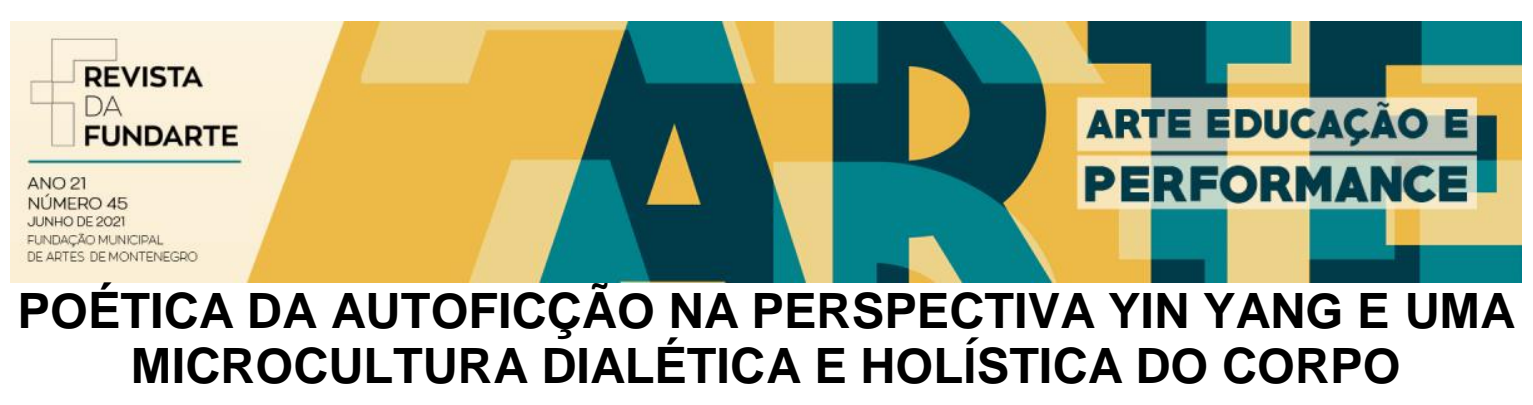

André Martins Ziegler ${ }^{1}$

\begin{abstract}
Resumo: $O$ artista-pesquisador contemporâneo, que investiga poeticamente sobre a sua própria corporeidade, depara-se muitas vezes com questões paradoxais por tensionar os sentidos das relações que o estabelecem no mundo. A partir dessa percepção, essa escrita pretende refletir algumas questões a respeito de uma poética da autoficção pela perspectiva do Yin Yang. Já que esta poética evidencia uma corporeidade que a todo momento articula imagens paradoxais em um processo de sensibilização e constituição de uma micropolítica holística e dialética do corpo.
\end{abstract}

Palavras-chave: Autoficção; Corporeidade; Poética.

\title{
POETIC OF SELF-FICTION FROM THE YIN YANG PERSPECTIVE AND A DIALETIC AND HOLISTIC BODY MICROCULTURE
}

\begin{abstract}
The contemporary artist-researcher, who investigates poetically about his own corporeality, often across with paradoxical issues for tensing the senses of relationships that establish himself in the world. From this perception, this writing intends to reflect some questions about a poetics autofiction through the perspective of the Yin Yang. Since this poetic evidence a corporeality that all time articulates paradoxical images in a process of sensitization and constitution of a holistic and dialectical micro-politics of body.
\end{abstract}

Keywords: Autofiction; Corporeality; Poetic.

\section{INTRODUÇÃO}

\section{Um corpo paradoxal}

O artista pesquisador contemporâneo, que investiga poeticamente sobre a relação de si com o mundo, depara-se muitas vezes com questões paradoxais por tensionar os sentidos que estabelecem o próprio corpo na sociedade. Surgindo, assim, uma gama de poéticas contemporâneas que questionam as relações do corpo dos artistas com o espaço, tempo, com a cultura, com sistemas econômicos,

\footnotetext{
${ }^{1}$ Atua como artista-pesquisador com formação em Bacharelado Artes Visuais pela Universidade Federal de Pelotas, Mediador Artístico pelo projeto Patafísica: Mediadores do Imaginário e Agente Cultural pelo programa Fronteiras da Diversidade. Sua investigação poética permeia nas relações do afeto, subjetivação das experiências, universos fantásticos, experiência estética, corpo e corporeidade.
}

Disponível em: http://.seer.fundarte.rs.gov.br/index.php/revistadafundarte/index> 30 de junho de 2021. 


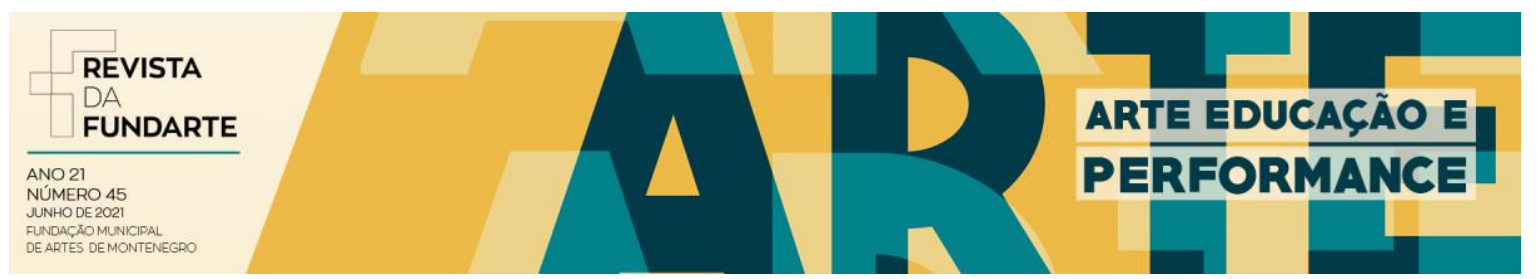

com a educação, com mitologias (universais e pessoais), religiões (ou a negação delas), objetos, com novas tecnologias, realidades virtuais, com outros corpos e entre outras mundanidades. Diante dessa constatação podemos refletir que o mundo do artista pode ser desvendado por articulações de elementos imagéticos dualísticos - imagens paradoxais. Ou ainda, que a corporeidade do artista atua como uma mediadora - que afeta e ao mesmo é afetada - de dualidades que moldam sua própria compreensão de corpo. Evidencia-se, assim, que nas poéticas contemporâneas do século XXI a identidade passa a ser percebida e sentida sempre em um constante processo de construção e desconstrução - processo este que me faz pensar enquanto um sujeito friccionado.
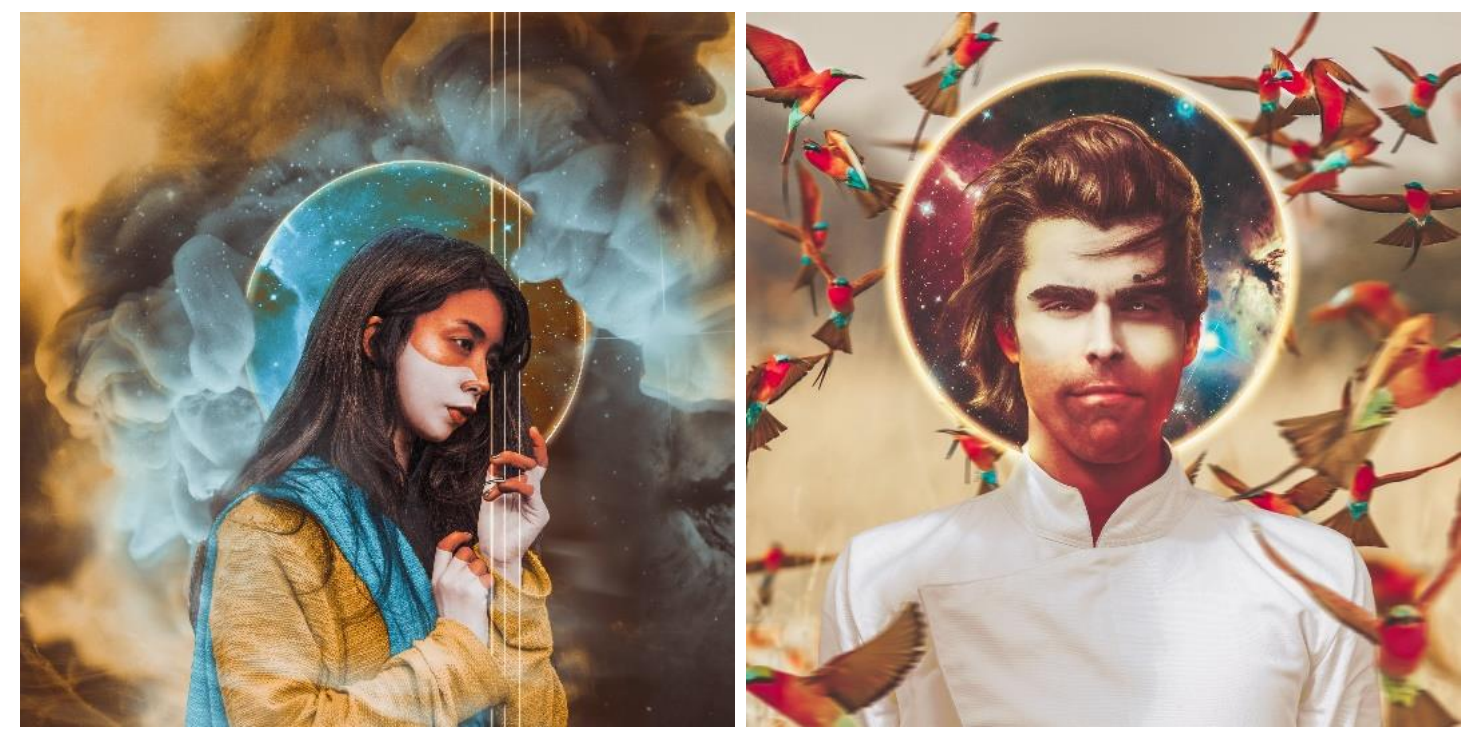

Figura 1 e 2 - "Ritma" e "Liberum". Fonte: acervo do autor.

Logo surge como interesse nesta reflexão poética pensar a respeito da minha corporeidade $^{2}$, já que está vem sendo revelada - durante minhas vivências artísticas

\footnotetext{
${ }^{2}$ Conforme Bernadete Machado, Merleau-Ponty nos diz que uma compreensão total do esquema corporal não diz respeito apenas à relação do sujeito com si, mas à sua relação com o outro. E ainda que $\mathrm{o}$ a percepção de corpo não se reduz ao sistema biológico e neurológico, mas também a sistemas subjetivos de afetos. Aí se faz uma força (corporeidade) que tenciona a relação corpo e mundo mutuamente.
} e holística do corpo. Revista da FUNDARTE. Montenegro, p.01-16, ano 21, o 45, junho de 2021.

Disponível em: http://.seer.fundarte.rs.gov.br/index.php/revistadafundarte/index> 30 de junho de 2021. 


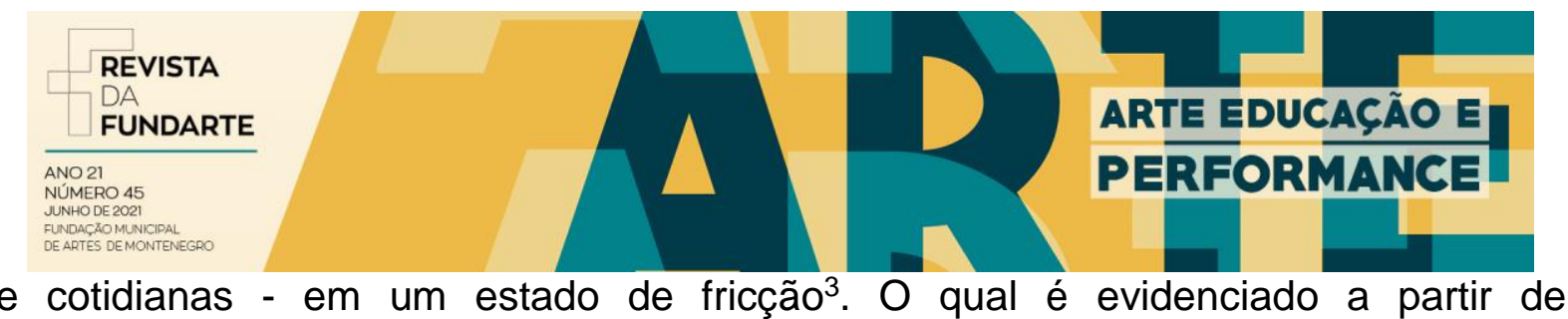

experiências artísticas com a criação de imagens fantásticas - feitas pelo processo de fotografia e edição digital - e escritas literárias - acadêmicas e fictícias -, a quais constituem uma poética da autoficção. Como aporte para se pensar um corpo paradoxal, que é acionado por uma corporeidade que a todo momento realiza a mediação de elementos imagéticos ${ }^{4}$ de valores dualísticos - como o homem $x$ mulher, masculino $x$ feminino, subjetivo $x$ objetivo, emocional $x$ racional, espiritual $x$ material, real $x$ surreal, éter $x$ atômico, fogo $x$ água, céu $x$ terra, natureza $x$ cidade, luz x escuridão -, será utilizado o artigo "Yin Yang: A New Perspective on Culture" do pesquisador Tony Fang.

\section{Entre sensível e o embrutecido}

As percepções acerca do meu corpo e corporeidade tomam maior profundidade a partir da minha pesquisa em graduação em Artes Visuais, a qual trata da problemática de que os processos de criação estão condicionados por uma cultura mercantilista, materialista e normatizadora. Dessa maneira o meu olhar é contaminado pelo modo operante do artista-pesquisador de desanuviar as relações de si com o mundo. Fazendo-me perceber o quanto as nossas percepções cognitivas e subjetivas - que fomentam os meus processos criativos tanto no campo das artes visuais como fora dele - estão impregnados por valores normóticos (heterossexual, cristão, colonial, machista, etc). Logo passo a evidenciar dois estados em oposição do meu corpo: um sensível, ao criar imagens por meio de processos poéticos, e outro embrutecimento, ao [re]produzir imagens vazias em afeto nos processos escolares e empresariais.

\footnotetext{
${ }^{3} \mathrm{~A}$ fricção é resultante das ações de atrito, esfregação, limpeza e resistência a partir do contato entre dois corpos. Penso nessa escrita uma analogia de que o meu corpo possuí dois estados (sensível e embrutecido) em contato (embate).

${ }^{4}$ Uso o termo elementos imagéticos para referir a alguma coisa e/ou fenômeno que transmite valores culturais e sociais por meio de um poder visual e estético, o qual fricciona as percepções dos sujeitos acerca de seus respectivos corpos e corporeidades. Por exemplo, o elemento imagético gênero possuí os aspectos feminino e masculino que são transmitidos pela percepção estética de que o masculino é representando pela cor azul e o feminino pela cor rosa.
}

Disponível em: http://.seer.fundarte.rs.gov.br/index.php/revistadafundarte/index> 30 de junho de 2021. 


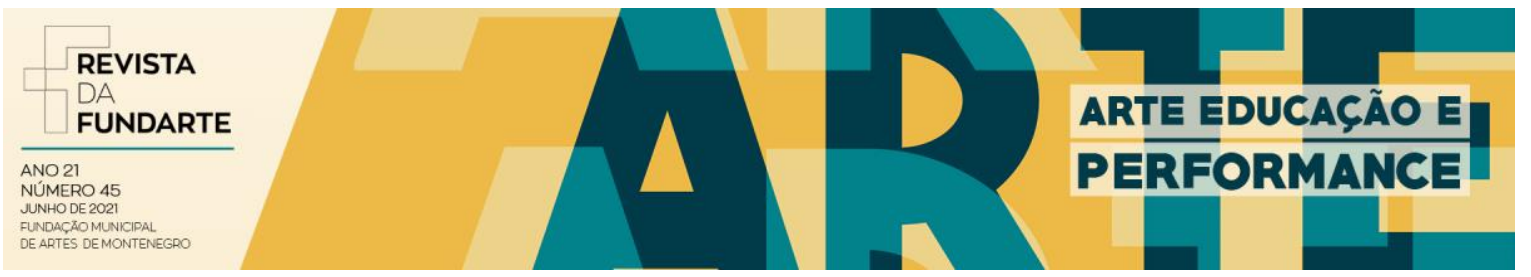

Elucida-se, assim, dois sintomas da contemporaneidade a qual meu corpo vivencia: uma fraca consciência da própria corporeidade nos processos de criação, principalmente fora do campo das poéticas em artes, e a apartação dela por conta de uma indústria demasiadamente mercantilista, que a todo momento dispara imagens espetaculares ${ }^{5}$ para promover o consumo.

Logo após a minha graduação em Artes visuais, esta investigação poética segue com criações imagéticas e literárias que usufruem da oposição entre um sujeito poético (sensível) e um sujeito normótico (endurecido). Surgindo, dessa maneira, narrativas fictícias, que hora tratam de vivências e reflexões de um mundo visto e dito real - relacionadas principalmente com a minha atuação profissional em empresas de publicidade e fotografia (2016 - 2019) - e outra com dramas e soluções imaginárias de um mundo fantástico e surreal - a partir de insights e inspirações oriundos de diversas experiências (estéticas, sentimentos, artísticas etc).
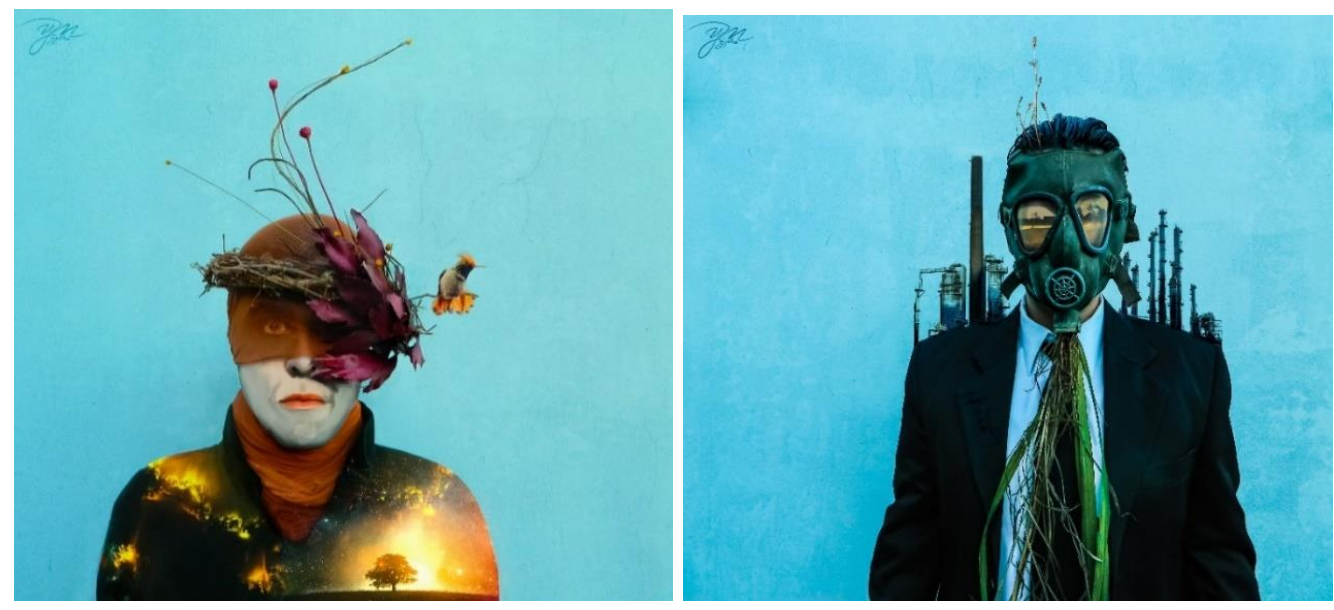

Figura 3 e 4 - "Aurantiacis Nebulae [Nebulosa Laranja]" e "Piratas Inanis Inertiae [Ainda Respiro]". Fonte: acervo do autor.

Conseguinte a essas experiências - da produção de imagens poéticas e a da atuação profissional no mercado de publicidade e fotografia - ingresso no mestrado

\footnotetext{
${ }^{5}$ Imagens espetaculares são aquelas que conquistam o imaginário humano através da imposição de uma mídia, cooperação ou emoção. Por exemplo a igreja católica conquistou o imaginário da população ocidental com anjos e santos junto com valores puritanos, machistas e homofóbicos. Ou ainda a imagem de um hamburguer de alguma rede de fast food, a qual convence o consumidor mesmo sendo uma comida maléfica a saúde. Mas há também aquela imagem espetacular que toca o nosso íntimo, como por exemplo se emocionar ao ver um show de opera ou peça de dança.
} e holística do corpo. Revista da FUNDARTE. Montenegro, p.01-16, ano 21, o 45, junho de 2021.

Disponível em: http://.seer.fundarte.rs.gov.br/index.php/revistadafundarte/index> 30 de junho de 2021. 


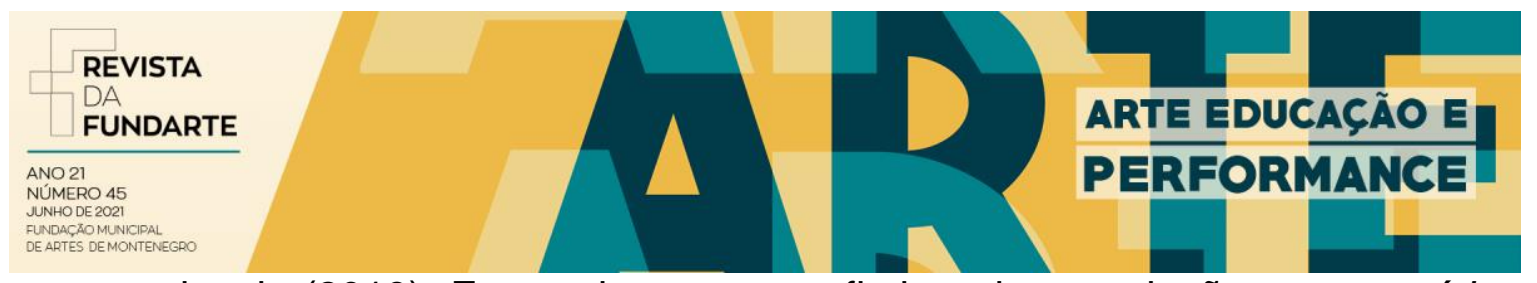

em artes visuais (2019). E percebo que ao refletir, sobre a relação corpo poético $x$ corpo normótico ${ }^{6}$, é interessante aprofundar e sensibilizar o meu olhar sobre uma microcultura holística e dialética do corpo.

Dessa maneira, procuro pensar sobre o meu processo de criação de imagens em artes visuais, surgindo a percepção de uma poética da autoficção - que se dá através de articulações de fluxos de imagéticos reais e ficcionais percebidos por meio do olhar, das memórias, revistas, outdoors, lentes da câmera fotográfica e interfaces digitais.

Por conseguinte, então, investigo que o termo autoficção foi criado pelo escritor, professor, tradutor e crítico Serge Doubrovsky (1928) na França. Durante a sua carreira pluralística Doubrovsky fazia da escrita um exercício estrutural de narrativas tautológicas, as quais referenciava suas próprias obras umas nas outras, independentemente, se fosse de gênero ensaístico ou romântico - ficando reconhecido, assim, por praticar uma escrita que rompia fronteiras entre gêneros literários. A partir de suas bibliografias mescladas com ficção, Doubrovsky refletia sobre a existência de uma "psicanálise existencial" em suas próprias obras, a qual o escritor "define como tributária de um amálgama de trabalhos de Sartre, MerleauPonty, Marx, Freud e Hegel." (NOGUEIRA, 2019, pg. 6151).

\begin{abstract}
Nessa sua "psicanálise existencial", o crítico privilegia o homem - o autor enquanto ser definido histórica e culturalmente. Mais especificamente, descobre-se, à leitura de seu livro sobre a Nova Crítica (1966), por exemplo, que Doubrovsky considera que uma obra é uma trama, uma "rede infinita de significações" respectivas ao texto impresso, mediatizada por um "universo imaginário" (DOUBROVSKY, 1966, p.101) em cujo centro está um homem definido historicamente, importando-lhe, porém, a existência imaginária do homem, e não sua biografia; e, sobremaneira, interessa-lhe o resultado de sua linguagem, que alinhava, na obra, o seu universo imaginário numa infinitude de significações (ibidem, passim). Assim, o autor, tal como estudado pelo crítico Doubrovsky, é um homem definido por sua linguagem: homem disseminado pelo texto marcadamente através de suas repetições e composições semânticas. (NOGUEIRA, 2019, pg. 6151).
\end{abstract}

Logo desde o cerne do termo autoficção, no campo da literatura, pode-se evidenciar que essa poética trata de uma linguagem feita por redes de significações

\footnotetext{
${ }^{6}$ Corpo poético trata daquele curto estado de criação, o qual o corpo afasta todos anseios, medos e problematizações que impregnam nosso modo criar. Corpo normótico é aquele que normaliza um estado vazio sem afeto, medo. Um corpo que não se emociona ou que só atua em função de uma lógica mercantilista, sem refletir os valores dos elementos imagéticos que o atravessa.
}

ZIEGLER, André Martins. Poética da autoficção na perspectiva Yin Yang e uma Microcultura dialética e holística do corpo. Revista da FUNDARTE. Montenegro, p.01-16, ano 21, no 45, junho de 2021.

Disponível em: http://.seer.fundarte.rs.gov.br/index.php/revistadafundarte/index> 30 de junho de 2021. 


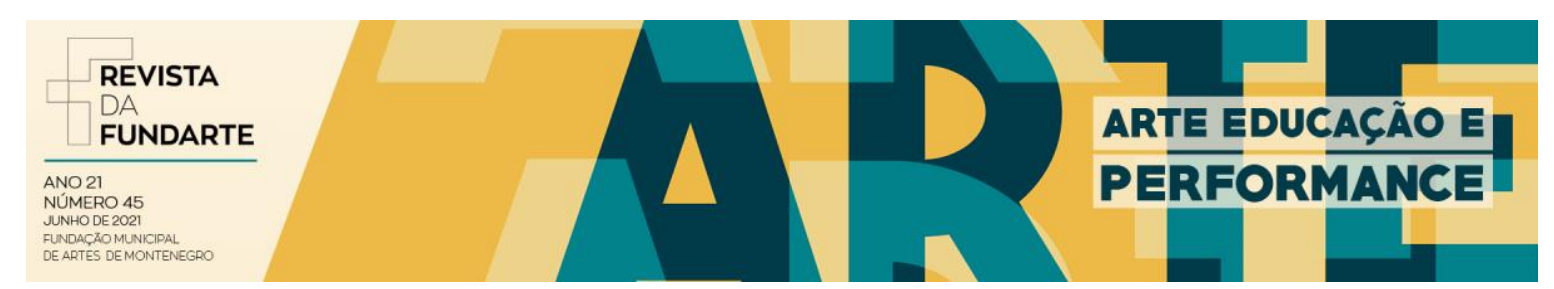

articuladas por uma dualidade maior: o real e o ficcional. Tornando interessante pensar a poética da autoficção, contextualizada dentro das minhas narrativas poéticas, pela filosofia chinesa Yin Yang - visto que estas narrativas, desenvolvidas na forma imagens e textos, são impulsionadas por um embate dualístico entre um corpo que hora se sente aparatado, por um modo de produção normótico, e outra sensibilizado, por um momento de criação poética.

\section{DESENVOLVIMENTO E DISCUSSÃO}

\section{Uma poética dualista}

A partir da percepção de que a autoficção no contexto desta produção artística trata de uma poética dualista, procuro compreender o porquê de meu corpo imergir nessa jornada poética. Questionando-me que elementos imagéticos ${ }^{7}$ a minha corporeidade articula nesta dualidade corpo poético $x$ corpo normótico?

Parto, assim, da percepção de que na contemporaneidade do século XXI o olhar do sujeito reeducou-se, de maneira que ele percebe não só o próprio corpo de forma imagética, mas o mundo também. O que torna interessante exercitar uma breve análise de quais elementos imagéticos atravessam o meu corpo e seus aspectos duais, que de alguma forma influencia a performatividade de minha corporeidade:

\{sexo: homem $x$ mulher | gênero: rosa $x$ azul | classe: rico $x$ pobre | espaço: cidade $x$ natureza | espiritualidade: anjo $x$ demônio | sistema: coletivista $x$ individualista | pensamento: cientifico $\mathrm{x}$ holístico | faculdade: exatas $\mathrm{x}$ humanas | mundo: oriente $\mathrm{x}$ ocidente | beleza: Vênus $\mathrm{x}$ Hércules | corpo: gordo $\mathrm{x}$ magro | esporte: futebol $\mathrm{x}$ ballet | cabelo: curto $x$ longo | brinquedo: carrinho $x$ boneca | elemento: fogo $x$ água | realidade: chata $x$ divertida | economia: capitalismo $\times$ socialismo | espiritualidade: cristianismo $\mathrm{x}$ satanismo | relacionamento: heterossexualidade $\mathrm{x}$ homossexualidade | ser humano: negro $\mathrm{x}$ branco | sociedade: empresários $\mathrm{x}$ tribos | desejo: novo $\mathrm{x}$ velho

\footnotetext{
${ }^{7}$ Uso o termo elementos imagéticos para me referir alguma coisa que concilia seu valor cultural e social com o seu poder visual e estético para formação de percepções acerca do corpo e corporeidade. Por exemplo o elemento gênero possuí aspecto feminino e masculino e agrega poder estético ao por cor azul como masculino e cor rosa feminina.
}

ZIEGLER, André Martins. Poética da autoficção na perspectiva Yin Yang e uma Microcultura dialética e holística do corpo. Revista da FUNDARTE. Montenegro, p.01-16, ano 21, o 45, junho de 2021.

Disponível em: http://.seer.fundarte.rs.gov.br/index.php/revistadafundarte/index> 30 de junho de 2021. 


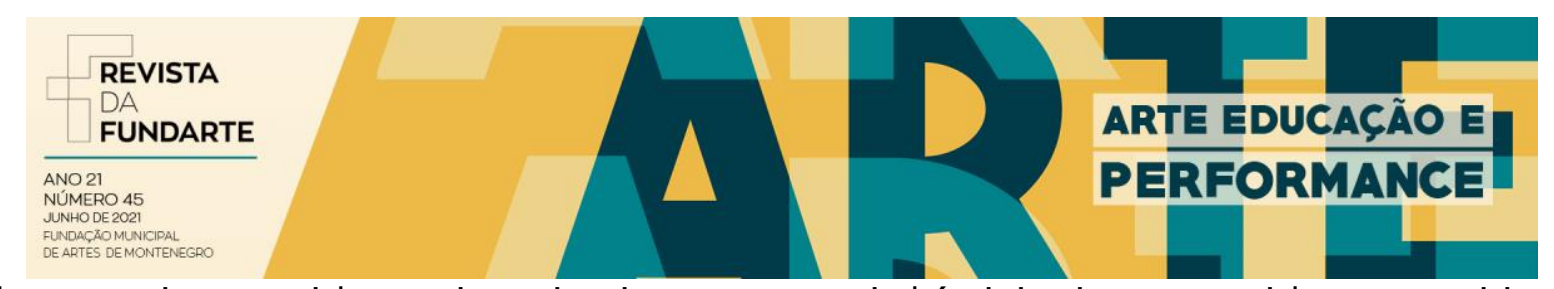

| astros: lua x sol | moral: puritanismo x sexual | índole: bem x mal | tempo: vida $\mathrm{x}$ morte\}

Pode-se constatar, em um primeiro momento, que os elementos imagéticos sentidos, reproduzidos e criados pela minha corporeidade constituem um aspecto dialético do corpo. Fazendo-me pensar que a potência de um corpo poético se dá, justamente, no embate desses elementos imagéticos, que tensionam os sentidos das relações que o estabelecem no mundo.

Visto isso, é encontrada como problemática o contexto no qual o meu corpo está inserido: uma cultura ocidental e brasileira que possuí uma visão polarizada desses elementos imagéticos. Em que estes ao constituírem uma gama de valores subjetivos, estéticos, morais, monetários e culturais - super polarizados, acabam por dedurparem o modo pelo qual os sujeitos percebem e se afetam por estes mesmos. Pois uma super polarização ocorre quando algum dos aspectos que compõe a dualidade desses elementos, deixa de consoar em harmonia, fazendo com que um fluxo entre as dualidades deixe de existir, estático - ou ainda, um estado de conservação que gera valores conservadores. Dessa maneira, propaga-se uma supremacia ou colonização dos valores que moldam nossas percepções corpóreas, por não haver um embate - reflexão - dos aspectos que esses elementos - e seus valores - carregam.

Para elucidar um pouco mais sobre esse processo na micropolítica do corpo, usarei como aporte a interpretação de cultura pela perceptiva do Yin Yang, desenvolvida por Tony Fang ${ }^{8}$ - pensando-se assim em uma analogia do macro pra 0 micro nesta escrita. Por primeiro precisamos compreender que Yin Yang é uma antiga filosofia chinesa, que incorpora uma visão holística, dialética e dinâmica do mundo (FANG, 2012). Tony Fang nos diz que Yin Yang possuí "três princípios" de dualidade:

The tenet of 'holistic duality' posits that a phenomenon or entity cannot be complete unless it has two opposite elements.... The tenet of 'dynamic

\footnotetext{
${ }^{8}$ Professor de Administração de Empresas em Stockholm Business School. Fang realiza pesquisas sobre a conceitualização da cultura na globalização, gestão e inovação transcultural, negociação comercial multicultural, liderança e comunicação intercultural, estilo de cultura e administração nórdica, estudos de negócios chineses, ciência política, negócios sino-russos relacionamento etc.
} e holística do corpo. Revista da FUNDARTE. Montenegro, p.01-16, ano 21, nำ45, junho de 2021.

Disponível em: http://.seer.fundarte.rs.gov.br/index.php/revistadafundarte/index> 30 de junho de 2021. 


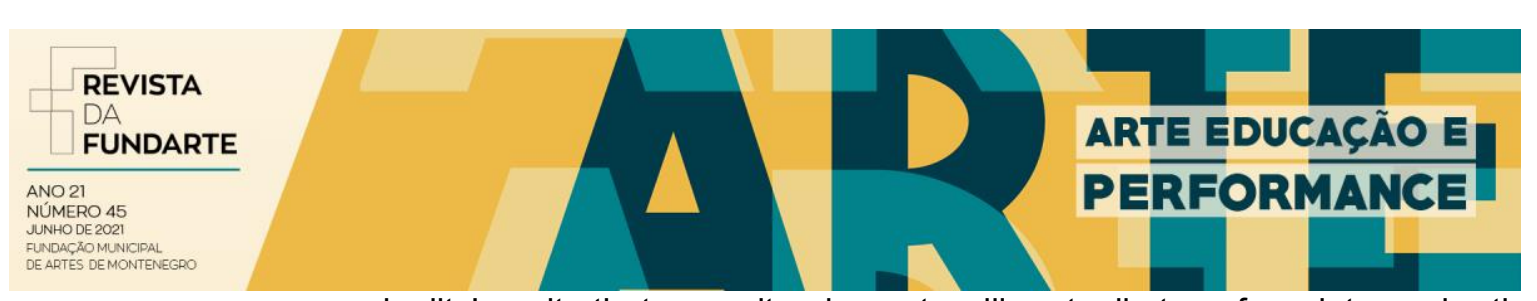

duality' posits that opposite elements will mutually transform into each other in a process of balancing under various conditions.... The tenet of 'dialectical duality' posits that the holistic and dynamic tenets can stand because two contrary (relatively contradictory) yet interdependent (relatively compatible) elements exist as opposites in unity to mutually affirm (for consistency and equilibrium) and mutually negate (for completeness and punctuated shift)....The dialectical tenet is the most salient as the anchor for the other two tenets of duality. (Li,2008: 416 apud FANG, 2012, pg.26).

(tradução livre do autor)

O princípio da 'dualidade holística' postula que um fenômeno ou entidade não pode ser completo, a menos que possua dois elementos opostos.... O princípio da 'dualidade dinâmica' suplica que estes elementos opostos transformarão um ao outro mutuamente em um processo de balanceamento sob diversas circunstâncias .... O princípio da 'dualidade dialética' suplica que os princípios holísticos e dinâmicos podem permanecer porquê dois elementos contrários (relativamente contraditórios), mas ainda assim interdependentes (relativamente compatíveis), existem como opostos na unidade para mutuamente afirmar (por consistência e equilíbrio) e mutuamente negar (por completude e troca pontuada) .... O princípio dialético é o mais saliente, como uma espécie de âncora dos outros dois princípios da dualidade. (Li, 2008: 416 apud FANG, 2012, pág. 26).

\section{A partir desse princípio Tony Fang problematiza a respeito de uma visão} dinamicamente estática da cultura proposta por Hofstede ${ }^{9}$, pois esta percebe os paradoxos entre os valores como um problema ou erro, e não como um fenômeno potente em aprofundar as dimensões da cultura. Assim, o pesquisador propõe compreendermos a cultura por uma visão holística, dinâmica e dialética Yin Yang, usando a metáfora de oceano para dizer que

[...] culture encompasses different values. Depending on the context, situation, and time, some values come to the surface while others remain dormant, at the bottom of the ocean, to be awakened under different circumstances in a way that "at any given point in time, some cultural values may become more salient, i.e., rise to the surface, while other cultural values may be temporarily suppressed or lie dormant to be awakened by conditioning factors at some future time" .(FANG, 2011, p. 6) (FANG 2012, p.37).

(tradução livre do autor)

9 Geert Hofstede (Haarlem, 2 de outubro de 1928) é um psicólogo holandês. Ele foi inspirado pelo culturalismo. Sua visão da cultura é baseada na definição dada pelo antropólogo americano Kluckhohn: "a cultura é o modo de pensar, de sentir e de reagir de um grupo humano, sobretudo recebida e transmitida pelos símbolos, e que representa sua identidade específica: ela inclui os objetos concretos produzidos pelo grupo. O coração da cultura é constituído de ideias tradicionais e de valores que estão ligados".

ZIEGLER, André Martins. Poética da autoficção na perspectiva Yin Yang e uma Microcultura dialética e holística do corpo. Revista da FUNDARTE. Montenegro, p.01-16, ano 21, no 45, junho de 2021.

Disponível em: http://.seer.fundarte.rs.gov.br/index.php/revistadafundarte/index> 30 de junho de 2021. 


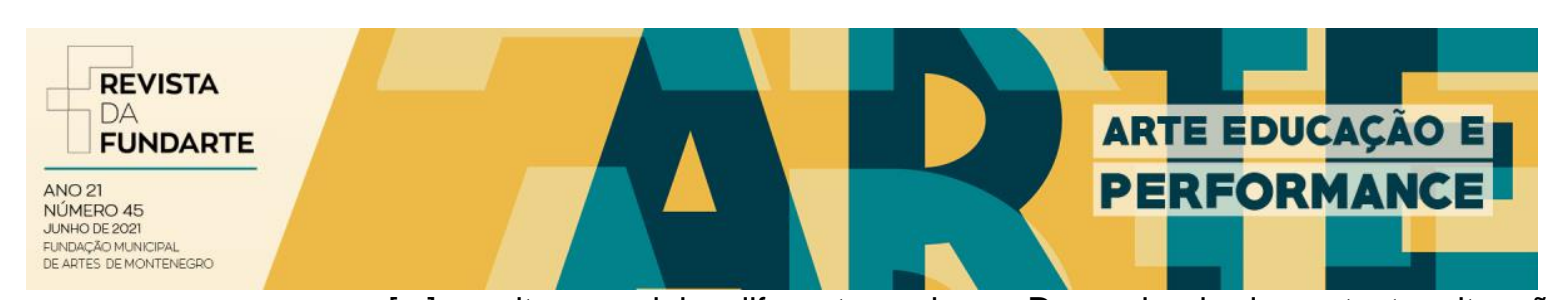

[...] a cultura engloba diferentes valores. Dependendo do contexto, situação e tempo, alguns valores vêm à tona, enquanto outros permanecem dormentes, no fundo do oceano, para serem despertados sob diferentes circunstâncias, de uma maneira que "a qualquer momento, alguns valores culturais podem tornarem-se mais salientes, ou seja, sobem à superfície, enquanto outros valores culturais podem ser temporariamente suprimidos ou permanecer adormecidos para serem despertados por fatores condicionantes em algum momento futuro ".(FANG, 2011, p. 6) (FANG 2012, p.37).

Em oposição a metáfora de cebola do autor Hofstede, o qual

[...] theorizes that "cultures, especially national cultures, are extremely stable over time" (p. 34) because the core values are stable. Hofstede (1991, 2001), uses an 'onion' metaphor to describe cultures. He maintains that an onion consists of different layers that can be peeled off until the core. At the core of the onion lie the basic assumptions, values, and beliefs which are stable because they are inherited. On the outer surfaces of the onion, we see symbols, heroes, and rituals that are 'practices' of culture (Hofstede, 1991). These outside layers, which are the behavioral parts of the model, may change over time. (FANG 2012, p.37).

(tradução livre do autor)

[...] teoriza que "culturas, principalmente as culturas nacionais, são extremamente estáveis ao longo do tempo" (p. 34), porque os valores fundamentais são estáveis. Hofstede $(1991,2001)$, usa uma metáfora de "cebola" para descrever culturas. Ele sustenta que uma cebola consiste em diferentes camadas, as quais podem ser descascadas até o núcleo. No cerne da cebola estão as suposições, valores e crenças básicas, que são estáveis por serem herdadas. Nas superfícies da cebola, vemos símbolos, heróis e rituais, que são "práticas" de cultura (Hofstede, 1991). Essas camadas externas, que são as partes comportamentais do modelo, podem mudar com o tempo. (FANG 2012, p.37).

A partir desse embate entre "oceano e cebola" pode-se pensar que nesta microcultura os símbolos, heróis e rituais atuam como elementos imagéticos que impregnam a pele do corpo - super-heróis de traços europeus, vida sexual baseada em dogmas cristões, redes sociais agindo como oráculos de uma vida ideal e feliz de modo que escurece as percepções do corpo para com a sua - e da própria corporeidade. e holística do corpo. Revista da FUNDARTE. Montenegro, p.01-16, ano 21, ํo 45, junho de 2021.

Disponível em: http://.seer.fundarte.rs.gov.br/index.php/revistadafundarte/index> 30 de junho de 2021. 


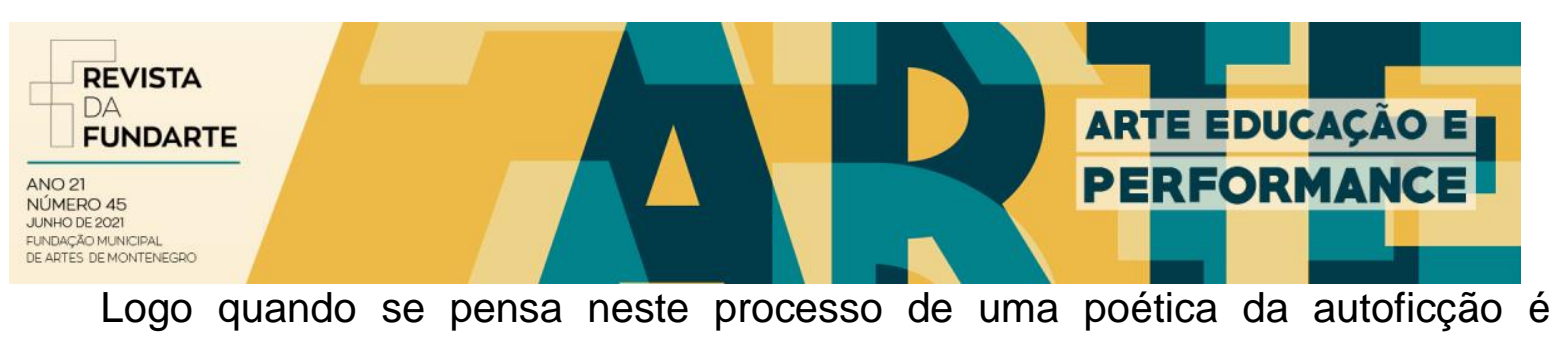
interessante pontuar que ao criar narrativas que mesclam o real e o ficcional, na produção de imagens poéticas, percebo que o meu corpo a longo tempo vem mesclando entre cebola e oceano. Cebola por estratificar e condensar certos valores de elementos imagéticas através da mimese, principalmente na faixa etária de infância e adolescência, e oceano por agitar e mergulhar estas camadas em um mar de experiências poéticas e sociais. Logo, o real e ficcional não diz respeito somente a nível estético, ou na produção artística, mas também pode ser pensando nível DNA do corpo. Pois este ao constar realidades diferentes do que está entre as camadas da cebola acaba por vivenciar um processo de articulação de valores paradoxais - até que algum dia se acaba por lançar ao oceano.

Reflete-se, então, que a articulação de valores paradoxais, percebidos em elementos imagéticos dualistas nesta poética, serve como uma força motriz para que esse corpo se "abra" ao oceano - cultura - pensando por Fang. Logo, o paradoxo real e ficção na poética da autoficção indica a existência de uma corporeidade que se faz potente por possuir uma força vital que provoca embate entre aquilo que já lhe é normal e aquilo que ainda lhe é estranho - mudança.

Como exemplo disso pegaremos a percepção de que eu tenho um corpo do sexo ${ }^{10}$ homem, o qual foi posto em uma cultura do gênero ${ }^{11}$ masculino. Recordo-me das roupas de cores azuladas, do calção do uniforme da escola, dos brinquedos em forma de carro, da educação física ser somente futsal para os meninos, do cabelo sempre curto, das suposições de que as garotas próximas a mim eram minhas "namoradinhas" - entre outras coisas que passam batidas, as nossas percepções de corporeidade na infância. Isso se dá por que o corpo sexo homem foi colonizado por um elemento imagético de gênero deturbado, pois este valoriza apenas um aspecto masculino do elemento gênero, excluindo, assim, o feminino e os possíveis outros entre e com estes - como por exemplo o gênero neutro, sem gênero, transgênero, cross genger entre outros. O gênero, um elemento fruto de construção social, acaba

\footnotetext{
${ }^{10}$ Formação física, orgânica, celular e particular que permite distinguir o homem e a mulher.

${ }^{11}$ Construção social sobre os elementos visuais, comportamentais e sexuais que um corpo deve ter de acordo, ou não, com seu sexo de nascença.
} e holística do corpo. Revista da FUNDARTE. Montenegro, p.01-16, ano 21, no 45, junho de 2021.

Disponível em: http://.seer.fundarte.rs.gov.br/index.php/revistadafundarte/index> 30 de junho de 2021. 


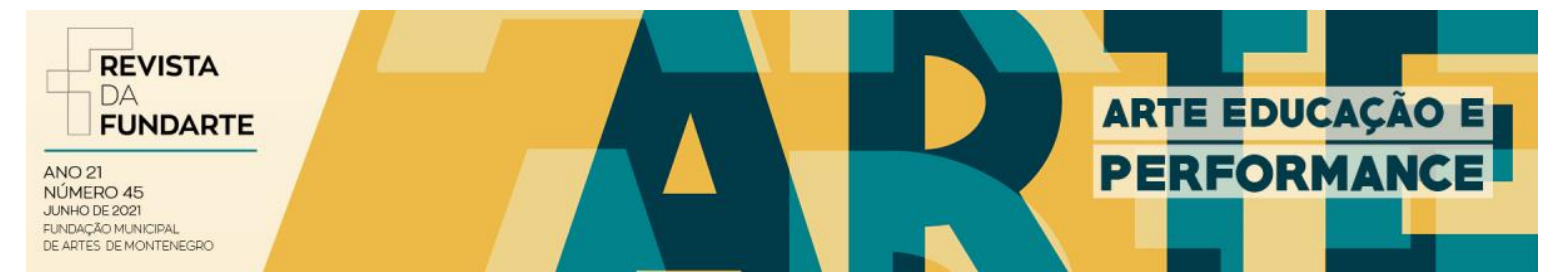

por obstruir a valorização de outras possibilidades de corpos sexuais - transsexual, assexual, intersexual entre outros. Por mais que estás sempre tenham existido, em decorrência de forças maiores do universo, ainda vivem em um estado de resistência constante diante de uma estratificação - por em camadas - sociocultural machista, heterossexual, branca e materialista.

Instaura-se, assim, microculturas de embrutecimento, que sufocam e escurecem as percepções da corporeidade. Apartando a capacidade de nascença do corpo de [re]criar-se - desenvolver, mudar, subverter - de acordo com o intimido, espiritual e sensível de cada indivíduo. Dessa perspectiva pode-se dizer que a "cebola", com as suas camadas, acaba por silenciar as redes de conexão que formam um coletivismo de diversidade dos corpos - coletivismos poéticos. Fazendome refletir que

O moderno promoveu a "privatização" da experiência artística, tendo centrado a dinâmica da arte na criação e um único indivíduo - o artista -, ensimesmado em suas certezas e imaginações... Induzido a criar distanciamento com sua audiência, sem expectativa de com elas interagir, ao contrário tentando desconhecê-la, o artista produzia sua arte isolado em seu mundo supostamente livre, motivado pelas coisas daquele mundo, como se eles - artista e seu mundo particular - se bastassem." (OLIVEIRA. 2011. p. 138). e holística do corpo. Revista da FUNDARTE. Montenegro, p.01-16, ano 21, o 45, junho de 2021.

Disponível em: http://.seer.fundarte.rs.gov.br/index.php/revistadafundarte/index> 30 de junho de 2021. 


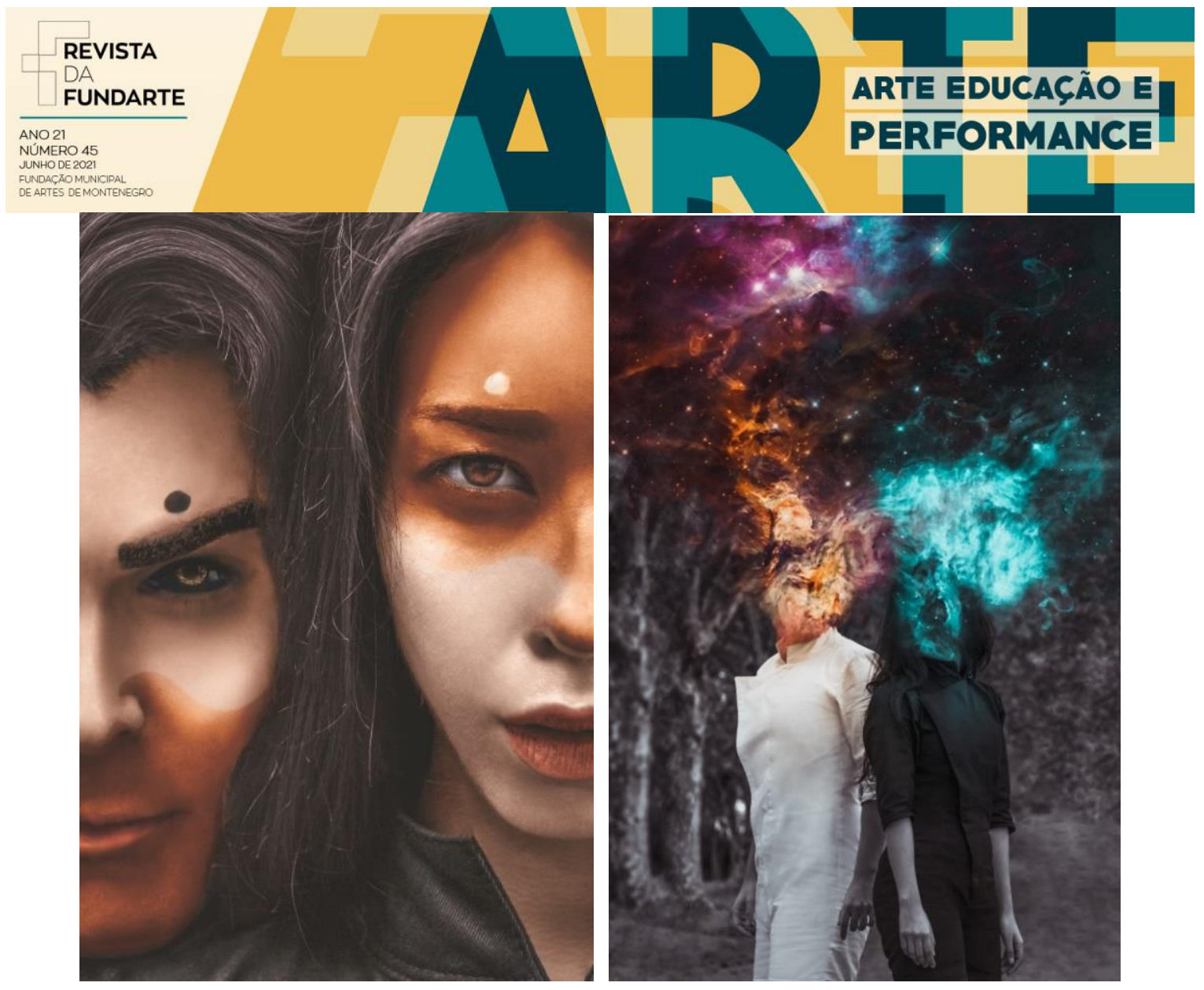

Figura 5 e 6 - "Yin Yang" e "Dialéticos". Fonte: acervo do autor.

Diante dessa constatação volto a me questionar que elementos imagéticos a minha corporeidade articula nesta dualidade corpo poético $x$ corpo normótico nesta poética da autoficção? Ao refletir a cultura na perspectiva da "cebola" para o "oceano" percebo que são muitos e infinitos. Pois o meu corpo quando sensibilizado e em estado fricção - que amolece e corrói essas camadas apartantes - percebe uma fenda para um universo caótico e rico em possibilidades.

\section{CONSIDERAÇÕES FINAIS}

\section{Humano Caos}

Diante dessa constatação, volto a me questionar que elementos imagéticos a minha corporeidade articula nesta dualidade corpo poético $x$ corpo normótico nesta poética da autoficção? Bom após refletir uma cultura na perspectiva Yin Ynag, percebo que são muitos e infinitos. Pois o meu corpo quando sensibilizado e em 


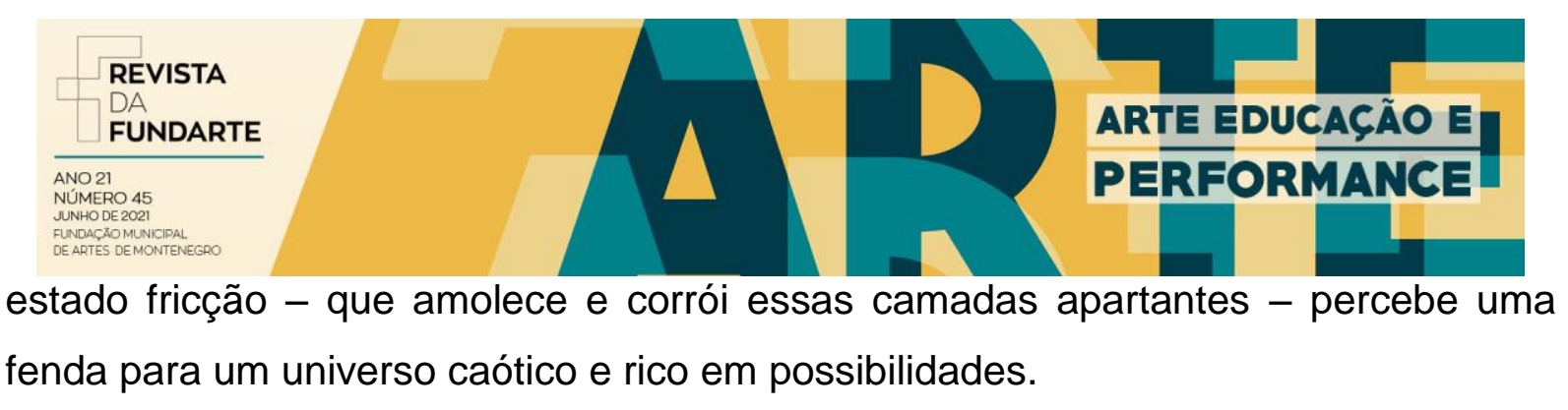

Não há mais apenas uma forma de realidade com seu respectivo mapa de possíveis. Os possíveis agora se reinventam e se redistribuem o tempo todo, ao sabor de ondas de fluxos, que desmancham formas de realidade e geram outras, que acabam igualmente dispersando-se no oceano, levadas pelo movimento de novas ondas. (ROLNIK, 1998, p.01).

Pensar esta micropolítica do corpo não só fortalece a minha corporeidade, mas, também, me faz pensar na importância de reavaliar a cultura ocidental e brasileira a partir de uma filosofia oriental. Pois do "ponto de vista de Yin Yang, contradições ou paradoxos não são vistos como problemas, mas como uma visão de mundo, uma metodologia e um modo de vida natural" (Chen, 2002; Chen, M.-J., 2008; Fang, 2003; Fletcher \& Fang, 2006; Li, 1998, 2008, 2011a, b apud FANG, 2012, p.36) (tradução livre do autor). Além disso é interessante atualizar as nossas percepções de microcultura de corpo e corporeidade, pois "estamos vivendo em um novo ambiente social de globalização com 'aprendizado cultural sem fronteiras e sem fio, transferência de conhecimento e compartilhamento sincronizado de informações" (FANG, 2012. p. 29) (tradução livre do autor).

Diante de um mundo com políticas conservadoras, radicais, reacionárias e apertadoras em ascensão, as percepções abordadas aqui indicam um caminho para contribuir com a sensibilização das percepções de uma cultura visual que conduz as percepções e relações dos corpos uns com outros e com o mundo.

Por final, percebo que ao ser levado por ressonâncias poéticas e intimistas da autoficção alcanço alguns momentos os quais me conecto novamente ao todo (caos) - luz e escuridão | coletivo $\mathrm{x}$ individual | pleno $\mathrm{x}$ vazio | homem $\mathrm{x}$ mulher. Alcançar um estado de felicidade e alta vitalidade requer $d x s$ artistas movimentos de mudanças, devires e fluidez, os quais descascam estratificações formadoras de realidades normóticas, inibindo o medo de lançar-se a um oceano cósmico sem fronteiras. Dessa maneira, a criação artística e a pesquisa poética apresentam-se como poderosas articuladoras e sensibilizadoras de camadas que embrutecem e e holística do corpo. Revista da FUNDARTE. Montenegro, p.01-16, ano 21, o 45, junho de 2021.

Disponível em: http://.seer.fundarte.rs.gov.br/index.php/revistadafundarte/index> 30 de junho de 2021. 


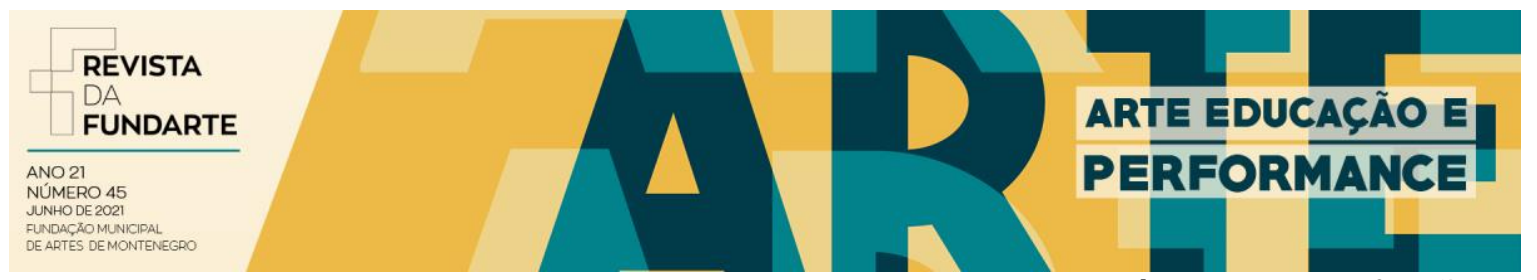

isolam os nossos corpos das estranhezas do mundo. Esta poética da autoficção me faz perceber a potência de resgatarmos a independência de nossos valores subjetivos e as potencias das [an]essências de nosso corpo, principalmente quando se é evidenciado que estamos cotidianamente sob processos de massificação dos corpos por meio de explosões imagéticas industriais vazias em afetos.

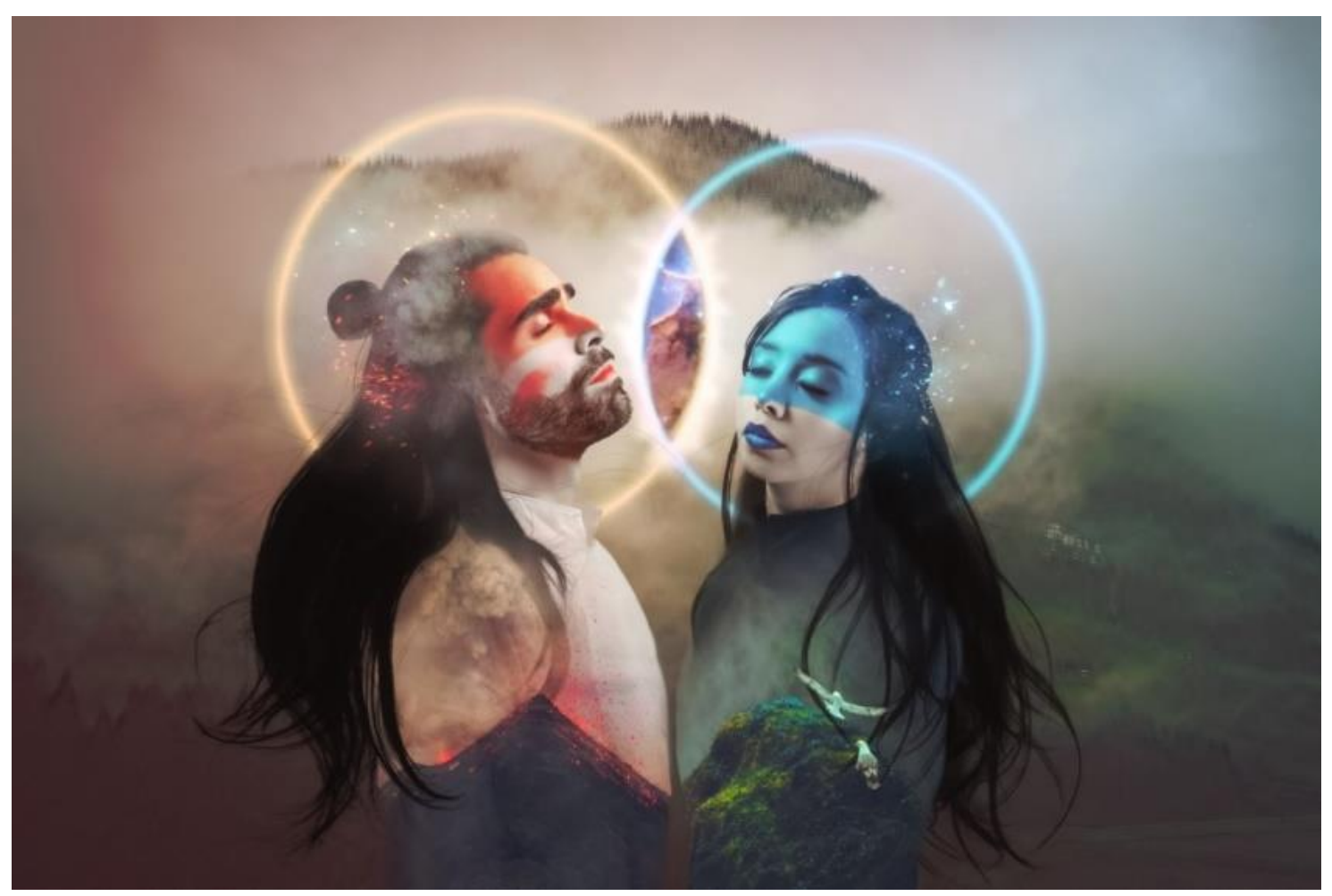

Figura 7 - "Pólos". Fonte: acervo do autor.

\section{Referências:}

BLUME, Bruno André. Progressismo: o que é?. Site "Politize!". Disponível em: www.politize.com.br/progressismo-o-que-e/ Acessado em: 02 de outubro de 2019.

FANG, Tony. Yin Yang: A New Perspective on Culture. Stockholm University. 2012. Disponível https://www.researchgate.net/publication/227792935_Yin_Yang_A_New_Perspective _on_CultureAcessado em: 31 de agosto de 2019. e holística do corpo. Revista da FUNDARTE. Montenegro, p.01-16, ano 21, nํ 45, junho de 2021.

Disponível em: http://.seer.fundarte.rs.gov.br/index.php/revistadafundarte/index> 30 de junho de 2021. 


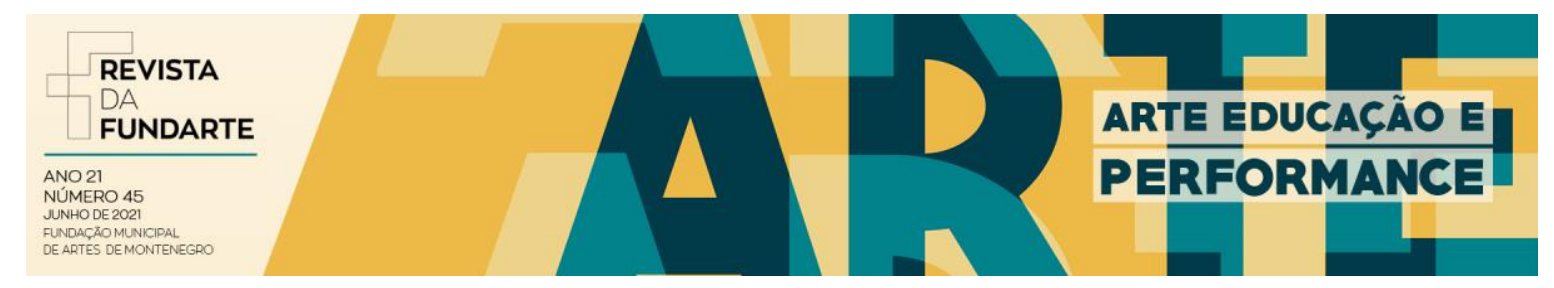

MACHADO, Bernadete Franco Grilo. Visão e Corporeidade em Merleau-Ponty. In: Revista Filosófica Argumentos. Ano 3, 2010, pp.82-88. Disponível em: www.periodicos.ufc.br/argumentos/article/view/18951

OLIVEIRA, Luiz Sérgio. A mundanidade da arte. Revista ARS v. 10, n. 20. Páginas 132-143. São Paulo. 2012.

NOGUEIRA, Luciana Persice. A autoficção de S. Doubrovsky e o registro da memória de si: obra em Si Bemol. In: Anais XV Encontro Abralic., 2016, pp. 61501658. Disponível em: www.abralic.org.br/anais-artigos/?id=1545

ROLNIK, Suely. CARTOGRAFIA ou de como pensar com o corpo vibrátil. Editora Estação Liberdade. São Paulo. 1998. Disponível em: http://www.pucsp.br/nucleodesubjetividade/suely\%20rolnik.htm Acessado em: 29 de agosto de 2017.

ROLNIK, Suely. Subjetividade Antropofágica. PUC - SP. São Paulo. 1998. Disponível em: http://www.pucsp.br/nucleodesubjetividade/suely\%20rolnik.htm Acessado em: 29 de agosto de 2017. e holística do corpo. Revista da FUNDARTE. Montenegro, p.01-16, ano 21, o 45, junho de 2021.

Disponível em: http://.seer.fundarte.rs.gov.br/index.php/revistadafundarte/index> 30 de junho de 2021. 